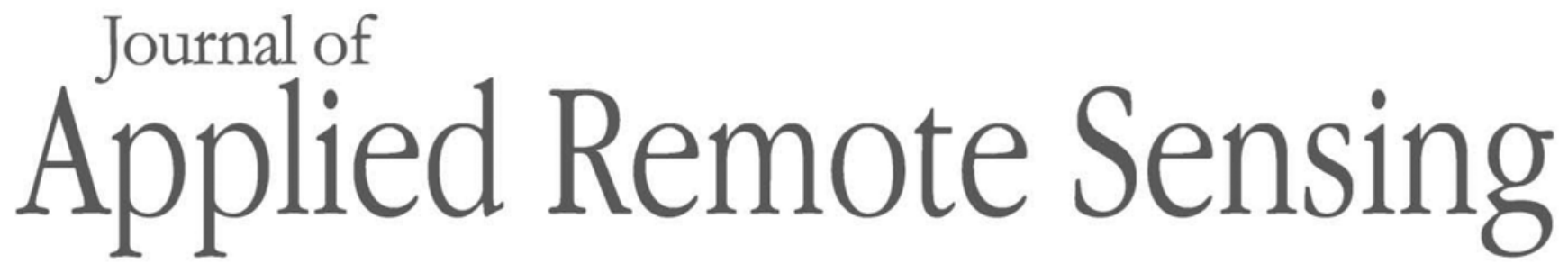

RemoteSensing.SPIEDigitalLibrary.org

\title{
Soil moisture index from ERS-SAR and its application to the analysis of spatial patterns in agricultural areas
}

Sabrina Esch

Wolfgang Korres

Tim G. Reichenau

Karl Schneider 


\title{
Soil moisture index from ERS-SAR and its application to the analysis of spatial patterns in agricultural areas
}

\author{
Sabrina Esch, Wolfgang Korres, Tim G. Reichenau, and Karl Schneider* \\ University of Cologne, Institute of Geography, Department of Geosciences, \\ Albertus-Magnus Platz, Cologne, Germany
}

\begin{abstract}
Soil moisture is an important factor influencing hydrological and meteorological exchange processes at the land surface. Synthetic aperture radar (SAR) backscatter is strongly affected by the volumetric soil moisture content, thus providing the potential to derive spatially distributed soil moisture information. Archives of historic SAR data exist, in which the use is limited by the lack of corresponding ground truth measurements. This study analyzes the potential of using a soil moisture index (SMI) with high spatial resolution to assess the soil moisture status in the absence of ground truth data. The index method is applied to agricultural areas in the catchment of the river Rur in Germany. The SMI was evaluated using antecedent precipitation and the wetting and drying behavior. The spatial patterns of the SMI were analyzed using semivariograms. This study confirms the applicability of a high resolution soil moisture index for monitoring near-surface soil moisture changes, to analyze soil moisture patterns, and indicates the possibility to complement antecedent precipitation as an input to hydrological models. $\odot$ The Authors. Published by SPIE under a Creative Commons Attribution 3.0 Unported License. Distribution or reproduction of this work in whole or in part requires full attribution of the original publication, including its DOI. [DOI: 10.1117/1.JRS.12.022206]
\end{abstract}

Keywords: soil moisture; synthetic aperture radar; agriculture; spatiotemporal patterns; antecedent precipitation.

Paper 170709SS received Aug. 8, 2017; accepted for publication Mar. 15, 2018; published online Apr. 10, 2018.

\section{Introduction}

Soil moisture is one of the main drivers of the complex soil-vegetation-atmosphere exchange processes. It determines how incoming solar radiation is partitioned into sensible and latent heat flux and to what extent precipitation results in surface runoff and infiltration. Therefore, it influences the energy and water budget at the soil surface. Moreover, plant growth and thus food production strongly depend upon the availability of soil moisture. Understanding soil moisture dynamic is important to understand carbon and nitrogen fluxes at the land surface. Thus, soil moisture and its spatial and temporal patterns are of key importance for basic science as well as for application, as shown in various studies. ${ }^{1-5}$ However, due to the spatial heterogeneity of properties at the land surface in terms of soil properties (e.g., soil texture) and terrain (e.g., slope) and due to many processes affecting the water fluxes within the soil-vegetation-atmosphere continuum (e.g., precipitation, water uptake, and evapotranspiration), soil moisture is variable, both in space and time.

There are different methods for estimating soil moisture, which can be grouped into in-situ measurements, models, or remote sensing. While in-situ measurements give the most accurate results, they are time- and cost-intensive and only provide point information. They are typically used for calibrating and validating model results and/or remote sensing products. Likewise, spatially distributed soil-vegetation-atmosphere models require in-situ measurements for model parametrization and validation. Those models provide spatially distributed, continuous data with high temporal but mostly with poor spatial resolution. Alternatively, airborne or satellite-based remote sensing can provide spatially distributed soil moisture information.

*Address all correspondence to: Karl Schneider, E-mail: karl.schneider@uni-koeln.de 
Both active and passive microwave remote sensing systems can be used to estimate near-surface soil moisture. While passive microwave remote sensing allows only a coarse spatial resolution, active microwave remote sensing, such as synthetic aperture radar (SAR), can provide highresolution near-surface soil moisture information. Compared to modelled soil moisture that can be provided continuously, the temporal resolution of remote sensing soil moisture products is rather low, as they give only snapshot information.

Near-surface soil moisture cannot be measured directly with radar remote sensing but is rather estimated. The principle of this estimation is well described ${ }^{1,5,6-10}$ and is based on the dependence of the backscatter intensity upon the dielectric constant of the observed medium. The relative dielectric constant $\varepsilon_{r}$ varies largely between air $(\sim 1)$, soil particles $(\sim 5)$, and water $(\sim 80)$. Therefore, in mixtures of dry soil, air, and water, variations in the relative dielectric constant, which implies variations in the backscatter intensity, mainly depend on changes in volumetric soil water content. The backscatter signal typically corresponds to a depth of half a wavelength of the radar system. Thus, remotely sensed soil moisture relates to the uppermost few centimeters of the soil. However, in addition to soil moisture, surface roughness and vegetation cover affect the backscatter intensity.

Researchers have developed theoretical, semiempirical and empirical models to retrieve soil moisture from radar remote sensing. ${ }^{11,12}$ Theoretical approaches ${ }^{13}$ model the backscattering behavior of incoming microwaves, based on incidence angle, frequency, surface roughness, and relative dielectric constant. These approaches require many input parameters, which are usually not available under practical conditions. Approaches exploiting the polarimetric information to decompose the backscattered signal and hereby correcting for vegetation and roughness effects ${ }^{14,15}$ need full polarimetric SAR data that are supplied only by few sensors (e.g., Radarsat-2, ALOS-2). Thus, empirical or semiempirical approaches are widely used instead, especially for vegetated areas. They require only a few input parameters, mainly pertaining to vegetation (e.g., type, growth stage, and biomass), surface roughness, and soil type. ${ }^{16-19}$ To get these input parameters, a large range of field measurements is needed. Moreover, these approaches are often restricted to areas similar to the calibration region. Applying a semiempirical inversion scheme ${ }^{19}$ that was developed for southern Germany, to our research catchment in western Germany in an earlier study, revealed a systematic overestimation when compared to measured near-surface soil moisture. In many regions of the Earth and for most historic datasets (such as the vast ERS archives), suitable ground truth data to validate semiempirical inversion schemes are unavailable. Thus, the application of empirical approaches may result in large errors.

Observing patterns of soil moisture is important to learn about underlying structures that influence the soil moisture distribution. The spatial variability of soil moisture for example changes with the level of soil moisture state, exhibiting lowest variability at the very dry and very wet state ${ }^{20}$ and its spatial structure exhibits a temporal course and a dependency on humidity. ${ }^{21,22}$ To find such relationships in remote sensing-based soil moisture requires the availability of remote sensing data at different moisture states and a time series of remote sensing data.

ERS-SAR data are now available since 1991. They provide a long time series of backscatter observations worldwide. However, the lack of ground truth measurements usually limits the use of these data for soil moisture studies. This paper presents an approach to derive a qualitative soil moisture index based on a time series of SAR data from the European remote sensing satellites (ERS-1 and -2). For many applications, such as the analysis of soil moisture patterns or drought monitoring, it is sufficient to know the moisture state in qualitative terms rather than absolute values. While most semiempirical approaches to determine soil moisture exploit the information contained in each image separately, multitemporal approaches have already been applied successfully, e.g., on RADARSAT- 2 data $^{23}$ and on low resolution ERS scatterometer data. ${ }^{24}$ The delta index model used pairs of acquisitions from ERS-2 and Radarsat- 1 to evaluate the soil moisture of a wet scene relative to a dry reference scene. ${ }^{11,25}$

The approach presented in this paper does not require in situ measurements of soil moisture and vegetation parameters and is based only on remote sensing data apart from ground truth data that has been used to train the land use classifications. Instead of giving absolute soil moisture values, it provides an index ranging from low to high soil moisture. This approach utilizes the 
vast ERS data archives to (i) assess the near-surface soil moisture status in regions lacking ground-based measurements and (ii) analyze near-surface soil moisture patterns. Direct validation of the approach is not possible due to the lack of in-situ soil moisture. Therefore, two approaches to evaluate the index are presented: (a) drying and wetting cycles of tandem scenes and (b) comparison to antecedent precipitation.

The study was done in the framework of the Transregional Collaborative Research Centre (TR) 32: patterns in soil-vegetation-atmosphere systems. The focus of TR 32 is to detect and better understand interactions of spatial and temporal patterns in the soil-vegetation-atmosphere continuum.

\section{Study Area and Datasets}

The soil moisture index approach is demonstrated on the catchment of the river Rur, which is the research area of TR 32. The catchment is located at the German-Belgium-Dutch border region (Fig. 1). From its source in Belgium to the outlet into the Maas river in the Netherlands, the river Rur has a length of $\sim 165 \mathrm{~km}$. The catchment covers an area of $\sim 2354 \mathrm{~km}^{2}$ and can be separated into two major landscape units, the low mountain range with Eifel and Hohes Venn in the south and the fertile loess plain in the north.

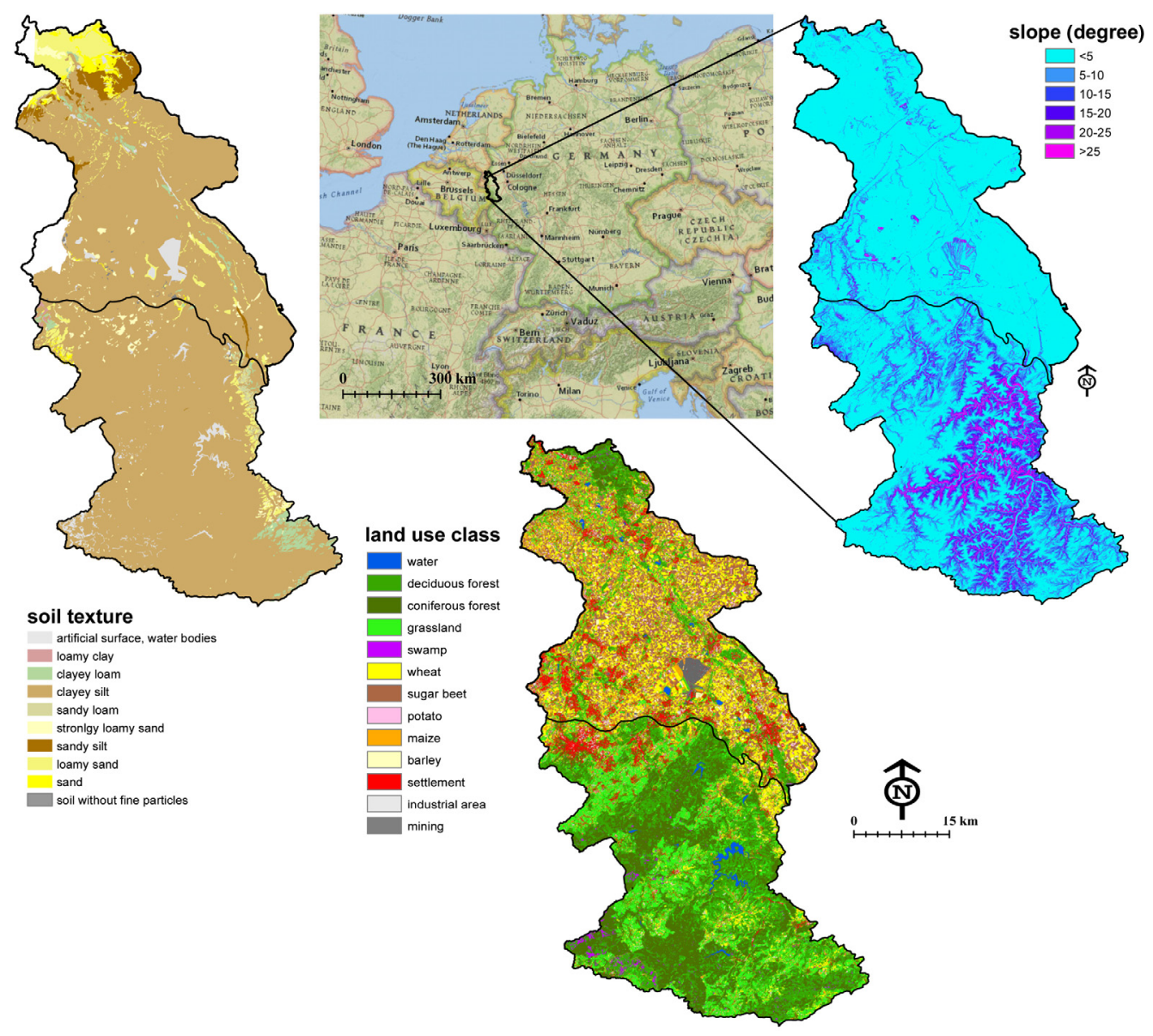

Fig. 1 Catchment of the river Rur with main land use types $2001,{ }^{26}$ slope and soil texture (source: Geological Survey of North Rhine-Westphalia). The northern part of the fertile loess plain with mainly agricultural regions can clearly be distinguished from the southern part, the low mountain range of the Eifel with dominating grasslands and forests. The background map was created using ArcGIS ${ }^{\circledR}$ software by Esri. ArcGIS ${ }^{\circledR}$ and ArcMap $^{T M}$ are the intellectual property of Esri and are used herein under license. Copyright $\odot$ Esri. 


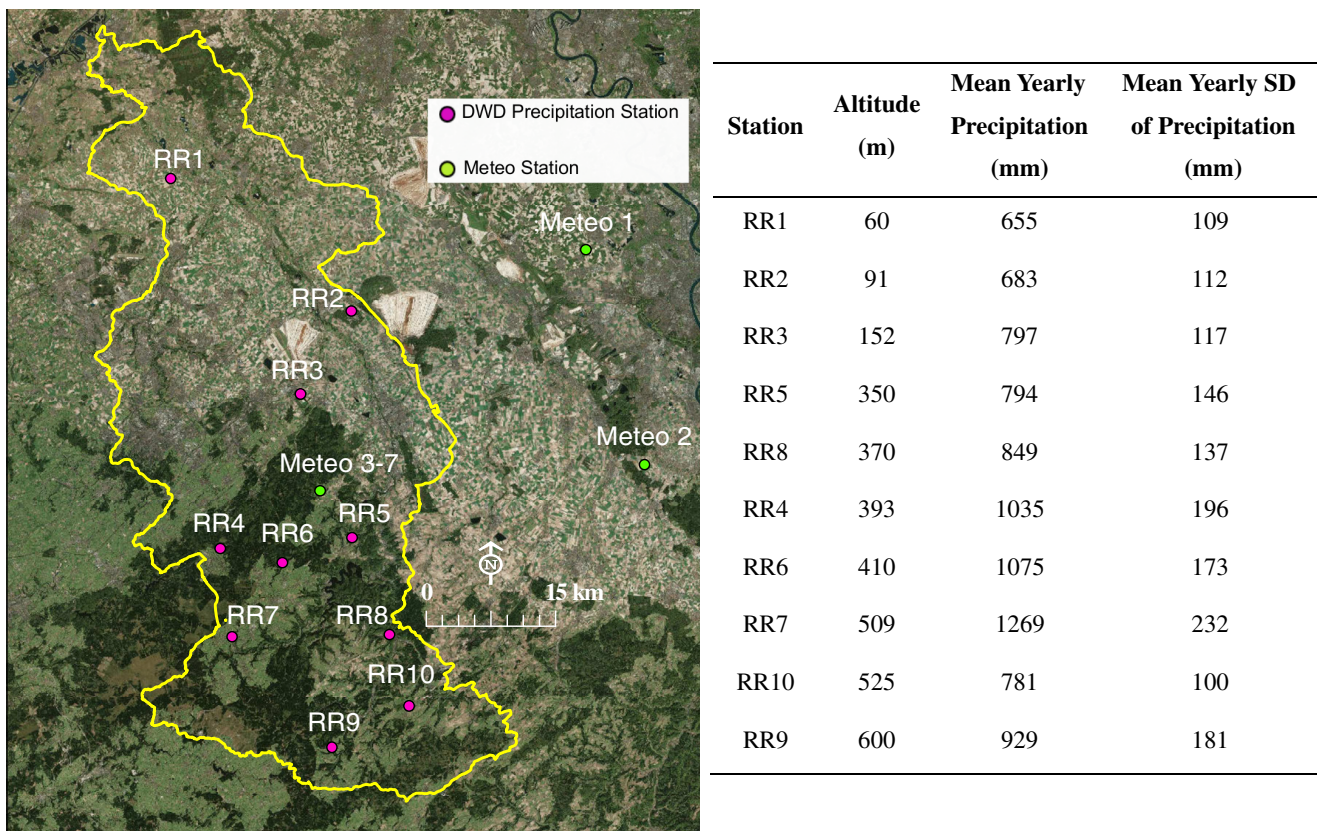

Fig. 2 Overview of the locations of the precipitation measurements as provided by DWD with corresponding station numbers and locations of meteorological stations. The table shows the mean annual precipitation and standard deviation of precipitation for each DWD precipitation station in millimeters. The stations are sorted by increasing altitude. The background map was created using ArcGIS ${ }^{\circledR}$ software by Esri. ArcGIS ${ }^{\circledR}$ and $\operatorname{ArcMap}^{\mathrm{TM}}$ are the intellectual property of Esri and are used herein under license. Copyright (C) Esri.

Major parts of the Rur catchment are agriculturally used, especially in the fertile loess plain, where agriculture is the dominant land use. In the low mountain range, forests and grasslands are the dominant land use classes. The typical soils that are found in the low mountain range are shallow Cambisols and Leptosols. In the fertile loess plain, Luvisols with a good air and water budget and optimal nutrient supply are characteristic. ${ }^{26}$ The dominant soil textural class in the Rur catchment is clayey silt, with sandy soils in the very northern part of the Rur catchment, which belongs to the Netherlands.

The climate in the watershed is humid. However, within the two major landscape units, significant differences in the rainfall distribution can be observed, whereas rainfall is relatively homogenous in the northern part of the catchment, ranging from 700 to $900 \mathrm{~mm} \mathrm{a}^{-1}$, the rainfall patterns in the southern part of the catchment are more heterogeneous (Fig. 2), due to elevation effects (Fig. 1). Here, rainfall ranges between $700 \mathrm{~mm} \mathrm{a}^{-1}$ in upwind and $1200 \mathrm{~mm} \mathrm{a}^{-1}$ in downwind direction. ${ }^{27}$ Due to the humid climate and the good water holding capacity of the soils, irrigation is not applied, apart from a few fields with specialized horticulture crops.

\subsection{Synthetic Aperture Radar Data}

For this study, we used 84 SAR single look complex images from the ERS-1 and -2 satellites, covering most parts of the catchment area. ERS-1 and -2 are twin satellites developed and operated by ESA from 1991 to 2000 and from 1995 to 2011, respectively. The SAR instrument on both satellites uses C-band $(5.6 \mathrm{~cm} / 5.3 \mathrm{GHz})$ in VV-polarization. ERS-1 and -2 operated with a fixed incidence angle of $23 \mathrm{deg}$. The SAR data were processed and georeferenced to quadratic $20-\mathrm{m}$ pixels. They represent the backscattering coefficient sigma nought. The processing included speckle filtering using a $3 \times 3$ Lee filter ${ }^{28}$ and geometric and radiometric terrain correction using a digital elevation model with $10-\mathrm{m}$ resolution. ${ }^{29}$ All SAR processing tasks were performed with the software packages SARscape 5.0 (sarmap SA, Purasca, Switzerland) and ENVI 5.1 (Exelis Visual Information Solutions, Inc., Boulder). 
Table 1 Overview of the 84 ERS scenes. Orbital node is differentiated by asc (ascending) and desc (descending). The mean 7-day antecedent precipitation (AP7) from 10 DWD stations for each acquisition date is given in millimeters.

\begin{tabular}{|c|c|c|c|c|c|c|c|c|c|c|c|}
\hline Date & ERS & Pass & AP7 & Date & ERS & Pass & AP7 & Date & ERS & Pass & AP7 \\
\hline March 17, 1995 & 1 & asc & 20 & October 22, 1996 & 1 & asc & 21 & April 11, 2000 & 2 & desc & 5 \\
\hline April 11, 1995 & 1 & asc & 7 & October 23, 1996 & 2 & asc & 21 & April 21, 2000 & 2 & asc & 3 \\
\hline April 27, 1995 & 1 & asc & 12 & March 18, 1997 & 2 & desc & 11 & May 10,2000 & 2 & asc & 15 \\
\hline May 22, 1995 & 2 & desc & 20 & March 28, 1997 & 2 & asc & 17 & May 16,2000 & 2 & desc & 20 \\
\hline June 02, 1995 & 2 & asc & 18 & April 16, 1997 & 2 & asc & 1 & May 26, 2000 & 2 & asc & 12 \\
\hline June 20, 1995 & 1 & asc & 14 & April 21, 1997 & 2 & desc & 2 & June 20, 2000 & 2 & desc & 2 \\
\hline July 06, 1995 & 1 & asc & 24 & May 20, 1997 & 1 & asc & 54 & July 25, 2000 & 2 & desc & 26 \\
\hline July 07, 1995 & 2 & asc & 24 & May 21, 1997 & 2 & asc & 60 & August 29, 2000 & 2 & desc & 13 \\
\hline July 31, 1995 & 1 & desc & 15 & May 27, 1997 & 2 & desc & 7 & Sept. 08, 2000 & 2 & asc & 18 \\
\hline August 01, 1995 & 2 & desc & 15 & June 06, 1997 & 2 & asc & 0 & October 03, 2000 & 2 & desc & 36 \\
\hline August 29, 1995 & 1 & asc & 32 & July 01, 1997 & 2 & desc & 35 & March 27, 2001 & 2 & desc & 42 \\
\hline Sept. 04, 1995 & 1 & desc & 11 & August 05, 1997 & 2 & desc & 18 & May 01, 2001 & 2 & desc & 24 \\
\hline October 03, 1995 & 1 & asc & 25 & August 15, 1997 & 2 & asc & 0 & June 05, 2001 & 2 & desc & 18 \\
\hline October 04, 1995 & 2 & asc & 23 & Sept. 09, 1997 & 2 & desc & 2 & April 16, 2002 & 2 & desc & 25 \\
\hline March 26, 1996 & 1 & asc & 9 & October 07, 1997 & 1 & asc & 7 & April 26, 2002 & 2 & asc & 6 \\
\hline March 27, 1996 & 2 & asc & 9 & March 23, 1999 & 2 & desc & 35 & May 31, 2002 & 2 & asc & 4 \\
\hline April 11, 1996 & 1 & asc & 5 & April 20, 1999 & 1 & asc & 36 & June 25, 2002 & 2 & desc & 3 \\
\hline April 12, 1996 & 2 & asc & 5 & April 27, 1999 & 2 & desc & 4 & July 05, 2002 & 2 & asc & 18 \\
\hline April 30, 1996 & 1 & asc & 3 & May 07, 1999 & 2 & asc & 18 & July 30, 2002 & 2 & desc & 24 \\
\hline May 01, 1996 & 2 & asc & 9 & May 26, 1999 & 2 & asc & 2 & August 09, 2002 & 2 & asc & 15 \\
\hline June 04, 1996 & 1 & asc & 10 & June 01, 1999 & 2 & desc & 21 & Sept. 03, 2002 & 2 & desc & 8 \\
\hline June 10,1996 & 1 & desc & 5 & June 10, 1999 & 1 & asc & 23 & October 08, 2002 & 2 & desc & 22 \\
\hline June 20, 1996 & 1 & asc & 6 & July 06, 1999 & 2 & desc & 22 & March 07, 2003 & 2 & asc & 29 \\
\hline June 21, 1996 & 2 & asc & 6 & July 16, 1999 & 2 & asc & 8 & April 01, 2003 & 2 & desc & 18 \\
\hline July 09, 1996 & 1 & asc & 28 & August 04, 1999 & 2 & asc & 2 & May 06, 2003 & 2 & desc & 17 \\
\hline July 25, 1996 & 1 & asc & 16 & August 10, 1999 & 2 & desc & 25 & June 10, 2003 & 2 & desc & 28 \\
\hline August 14, 1996 & 2 & asc & 29 & Sept. 14, 1999 & 2 & desc & 1 & July 15, 2003 & 2 & desc & 0 \\
\hline August 30, 1996 & 2 & asc & 90 & March 07, 2000 & 2 & desc & 37 & Sept. 23, 2003 & 2 & desc & 11 \\
\hline
\end{tabular}

Table 1 gives an overview of the ERS images that have been used in the analysis. Among them are images acquired in ascending and in descending node, thus incorporating different acquisition geometries. As we are only interested in relative backscatter intensities, we tested whether there are systematic differences between the distribution of means and variances of backscatter intensities for each orbit. Statistical $f$ - and $t$-tests performed with $\mathrm{R}$ software ${ }^{30}$ showed no significant differences between the distributions of backscatter intensities from ascending and descending orbits. We performed the same tests for ERS-1 and ERS-2 data. 
Also, these datasets showed no significant differences. Hence, we used images from ascending and descending orbits and from ERS-1 and ERS-2 jointly.

\subsection{Land Use Information}

To account for the vegetation impact on the backscattering coefficient, Landsat 5 thematic mapper and Landsat 7 enhanced thematic mapper plus images were used to derive annual land use maps. Ground truth information on land cover, which is needed for land use classifications, has been acquired through management records supplied by co-operating farmers. These management records encompass 150 fields in total and cover different crop types. Utilizing a maximum likelihood classification, land use maps for every year were produced with a spatial resolution of $30 \mathrm{~m}$. Since C-band penetrates only short vegetation types and bare soil, we concentrate on agricultural areas. Built-up and forest areas are excluded from our analysis. Within the agricultural areas, we differentiate between cereal, sugar beet, and grassland, as their roughness and dielectric properties are significantly different. Those are the main agricultural land use types in the Rur catchment, with a coverage of $15 \%$ (cereals), $13 \%$ (sugar beet), and grassland (15\%) in 2001 (Fig. 1) in the area of the Rur catchment.

Maize is of minor importance compared to the aforementioned land use classes but still covers $6 \%$ of the area of the Rur catchment. ${ }^{31}$ Nevertheless, since the ground truth data only comprise very few maize fields, maize fields were masked from the final land use classifications. Due to missing ground truth data between 1991 and 1994 and missing cloud-free Landsat data for 1998, land use information is only available from 1995 to 1997 and 1999 to 2003 . The overall accuracy of the land use maps for all years is between $82.4 \%$ (for 1999) and 99.4\% (for 2001), and the kappa-coefficient is between 0.59 (for 1999) and 0.98 (for 2001).

\subsection{Soil Moisture and Precipitation Data}

No in-situ surface soil moisture for validation is available for the study period and location. Therefore, precipitation data is used to evaluate the soil moisture index approach. The German Weather Service (DWD) provides daily-mean precipitation datasets for several stations within the Rur catchment over a long period. Ten stations, shown in Fig. 2, recorded data over the whole period of 1995 to 2003. They were acquired in the context of precipitation routine measurements performed by DWD and are publicly available from the Climate Data Center. ${ }^{32}$ The precipitation amounts in Fig. 2 show generally higher mean annual precipitation with increasing altitude of the station. In the eastern and western part of the Eifel region, topography-induced differences can be seen between stations.

To compare the relationship between antecedent precipitation data and in-situ near-surface soil moisture measurements in general, data from seven meteorological stations (Campbell Scientific) were used. Out of the seven stations, two provided data only in 2015 (Meteo 2 and Meteo 3) and the others provided data in 2016 (Meteo 1 and Meteo 4-7). Only data from the vegetation period (March to October) are used in the analysis. The stations recorded continuous precipitation heights and soil moisture at $5 \mathrm{~cm}$ depth. Volumetric soil moisture is measured with CSC616 soil moisture sensors (Campbell Scientific), using time-domain reflectometry. The stations were set up on agricultural fields from co-operating farmers in the Rur catchment. Daily precipitation sums and soil moisture means have been calculated. The measurements provided by overall eight meteo-stations were checked for consistency and homogeneity. As inconsistent data were found at one station, data from this station were excluded from further consideration. For this station, measurement errors like wrongly installed sensors are assumed.

\section{Methodology}

The method to derive the soil moisture index is based on two main assumptions: (i) the range of surface soil moisture is limited by the extreme states of soil moisture: saturation as the upper limit and the minimum water content of a given soil as the lower limit and (ii) with a given land 
use type, the variations of backscatter due to vegetation properties and surface roughness are much smaller than the variations of backscatter due to soil moisture.

The upper and lower limits of soil moisture are soil texture specific properties. The soil moisture index is a relative value between these two extremes. Against the backdrop of the climate conditions prevailing in our test area (see Table 1) and the large amount of ERS 1/2 observations, it can be assumed that within this data collective both states, the dry and the saturated, are represented.

However, as the backscattering signal depends not only on the surface soil moisture content but is also influenced by the vegetation properties (backscatter induced by vegetation geometry and plant water content) and soil surface roughness, ${ }^{33}$ estimating the soil moisture state from the backscattering coefficient requires the reduction or even elimination of these influencing factors. In agricultural area, which is the subject of the current study, both, vegetation properties and surface roughness can be described as a function of land use type (crop type, grassland, and bare soil) and time of year (phenological state and management activities). Assuming homogeneity of the backscatter impact of vegetation and surface roughness within a given land use class, variations of the backscatter depend only upon differences of soil moisture. For incidence angles comparable to ERS and under winter wheat, it has been found that the dominant scatterting mechanism is the soil scattering and the canopy only attenuates the backscatter. ${ }^{34}$ Consequently, the impact of spatial heterogeneities in vegetation parameters (e.g., biomass, structure) on ERS backscatter within a given land use type and phenological state is small compared to the impact of spatial heterogeneities in soil moisture. To homogenize the surface roughness and the attenuation effect of vegetation parameters, all backscatter intensity data were grouped according to land use type and month. Grouping by month made sure that the vegetation is at a comparable phenological state.

\subsection{Soil Moisture Index}

The available land use maps for each year distinguish sugar beet, cereals, and grassland pixels. All other areas are masked out, since, as explained in the data section, soil moisture retrieval with $\mathrm{C}$-Band is only possible for bare soil and agricultural land use types. The land use maps for each year were resampled to $20-\mathrm{m}$ resolution using a majority method and then georeferenced to a corresponding SAR scene. This was done for the ascending and descending node, respectively. To avoid mixed pixel effects, border pixels between two different land use types were masked using a dedicated filter that masks out pixels that are surrounded by more than $60 \%$ of pixels with a different land use type. Resampling and georeferencing were performed using ArcGIS (ESRI, Redlands).

For each land use group (cereals, sugar beet, and grassland) and month, histograms of the sigma nought values in $\mathrm{dB}$ were produced. The soil moisture index was then scaled to the 5 th and 95th percentiles of each histogram. Pixels outside of this range were discarded. Limiting the histogram analysis to these percentiles reduces spurious effects due to speckle or outliers. The interval between the two percentiles is then used to normalize the sigma nought values based on their position in the histogram. The soil moisture index (SMI) value for a given land use and month combination is calculated similar to Wagner et al. ${ }^{24}$ as follows:

$$
\mathrm{SMI}=\frac{\sigma_{0}-\sigma_{0 \mathrm{dry}}}{\sigma_{0 \mathrm{wet}}-\sigma_{0 \mathrm{dry}}} * 100,
$$

with $\sigma_{0 \text { dry }}$ being the 5 th percentile and thus representing the state of minimum saturation (dry state) of a given land use and month combination and $\sigma_{0 \text { wet }}$ being the 95 th percentile, representing the state of saturation (wet state) of a given land use and month combination. A simple linear indexing is used, because the relationship between surface soil moisture and radar signals is well described by linear relationships. ${ }^{35,36}$ The SMI can range between 0 and 100.

\subsection{Evaluating Soil Moisture Index Maps}

Typically, ground measurements taken during the satellite overflight are used to validate remotely sensed surface soil moisture data. However, for historic data like ours, these 
measurements are usually not available. Therefore, we used the following two step approach to validate the SMI: (1) by comparing soil moisture index maps of two consecutive days from ERS tandem acquisitions and investigating the drying and wetting behavior using precipitation measurements and (2) by correlating the qualitative soil moisture index maps with antecedent precipitation that was measured at DWD stations.

From August 17, 1995 until June 02, 1996, ERS-1 and 2 operated in the so-called tandem phase. During this phase but also beyond, several acquisitions were made from the same path with $24 \mathrm{~h}$ delay between the two satellite overpasses. Those tandem scenes can be used to observe short-term changes in soil moisture like drying or wetting of the soil surface. Other parameters that may influence the backscatter intensity (surface roughness and vegetation cover) can be assumed constant on such a short-time scale. Seven of those tandem scenes are available for our area and observation period. By calculating the differential SMI $(\Delta \mathrm{SMI})$ from two consecutive days and comparing it to precipitation data, we evaluated the resulting SMI maps in terms of soil moisture change. As the SMI comprises the values between 0 and 100, $\Delta$ SMI can take integer values between -100 (drying) and 100 (wetting).

Another way to validate the soil moisture index approach is to use antecedent precipitation data as a comparable quantity. Antecedent precipitation is used as an approximation to soil moisture when soil moisture data is unavailable. ${ }^{37,38}$ As antecedent precipitation is based on measurements at meteorological stations, its spatial resolution is rather coarse. Substituting or complementing antecedent precipitation with SMI would result in an improved spatial representation. However, this requires that a strong relationship between the soil moisture index and antecedent precipitation can be found.

For this analysis, 10 DWD precipitation (RR) stations (Fig. 2), which provide a complete time series of measurements and are located within our test area, were chosen. The mean SMI value for a region encompassing a 1-km radius around the DWD RR stations was calculated.

\subsection{Geostatistical Analysis}

One major purpose of our study is to understand the spatial heterogeneity of surface soil moisture. Spatial heterogeneity can be expressed by measures of spatial variability and spatial structure (e.g., the autocorrelation structure). ${ }^{39,40}$

Patterns of spatial variability were examined by analyzing the distribution of standard deviation throughout the Rur catchment. Therefore, standard deviation and mean SMI values were calculated from the single pixel values in $140 \mathrm{~m} \times 140 \mathrm{~m}$ nonoverlapping boxes. Only boxes that contain less than $30 \%$ of masked-out pixels were considered in the analysis.

The spatial structure was assessed using semivariograms. The experimental semivariogram describes how data correlate at distinct distances (given by the lag). The shape of a semivariogram can be described by three parameters: range, sill, and nugget. To parameterize their values, a curve, the theoretical semivariogram, is fitted to the experimental semivariogram. The range parameter can be used to describe the break between spatially correlated and uncorrelated values and hereby provides information about the spatial organization of soil moisture patterns. ${ }^{41}$ The sill describes the variance of uncorrelated values and the nugget describes small-scale variability and measurement error. Patterns in those variables can reveal patterns in the distribution of surface soil moisture. Experimental semivariograms have been calculated using the R package gstat, ${ }^{42}$ utilizing a maximum lag of $25 \mathrm{~km}$ and a lag class size of $200 \mathrm{~m}$. To fit the theoretical semivariograms, the ordinary-least-squares method has been used, employing an exponential model.

\section{Results and Discussion}

Prior to interpreting the soil moisture index, its performance must be evaluated. In the following paragraphs, the temporal course of backscatter for different land use types is assessed. Later, backscatter is compared to precipitation information in terms of wetting and drying events and to antecedent precipitation. 
Table 2 Minimal and maximal 7-day antecedent precipitation in mm from the 10 DWD RR stations over all acquisition dates per month.

\begin{tabular}{ccccccccc}
\hline \hline & March & April & May & June & July & August & September & October \\
\hline Min & 4.1 & 0 & 0.7 & 0 & 0 & 0 & 0 & 1.1 \\
Max & 75.1 & 64.2 & 129.5 & 43.5 & 69.5 & 137.9 & 42.3 & 58.3 \\
\hline \hline
\end{tabular}

The first assumption for the soil moisture index was that in our data, both the dry (minimum water content) and the wet states (saturation) are represented somewhere in the images for each month and land use type (cf. Sec. 3). When using the 7-day antecedent precipitation as an indicator for soil moisture state, we see that the range between minimal and maximal antecedent precipitation differs for each month (Table 2). The typical porosity of the soils in our test area varies between $37 \%$ and $49 \%$ for mineral soils based on the soil texture map BK 50 (Geological Survey of North Rhine-Westphalia) and the pedotransfer function implemented in the land surface model Community Land Model (CLM 4.5). ${ }^{43}$ Conventional agricultural management which dominates in our test site increases porosity. Assuming a porosity of $40 \%$ within the topmost $5 \mathrm{~cm}$, for example, leads to a saturated water content of $\sim 20 \mathrm{~mm}$ in the topmost $5 \mathrm{~cm}$ of the soil. Thus, the wet state should be represented well in our data. Depending on the evaporation rate, the topmost few centimeters of the soil typically dry within a few days after a rainfall event. Therefore, with the possible exception of March, also the dry state should be appropriately represented in our dataset.

The second assumption from the soil moisture index was that the influence of vegetation and surface roughness on the backscatter intensity is a function of vegetation type and phenological state. Therefore, we grouped the intensity data by vegetation type and month.

Monthly aggregation was used as a compromise between appropriately addressing the seasonal growth patterns and providing a sufficiently large sample to ensure that both the wet and the dry soil moisture state is represented by the data collective. Figure 3 shows monthly boxplots for the different vegetation types analyzed in this study. Corresponding to the increasing biomass, the backscatter intensity of cereals decreases from April to June. In July, cereal biomass dries due to senescence. In addition, in the end of July, cereal harvest begins. Therefore, the backscatter intensity increases again. After harvest, in August, September, and October, the backscatter intensity stays relatively constant on a high level. The range of the whiskers, representing extreme data points, is small compared to the other months.

The seasonality of sugar beet is less prominent than for cereals. Sugar beet generally accumulates biomass between the end of June and October, when it is harvested. In contrast to cereals, most biomass is located below ground. The sugar beet fruit also stores high amounts of water. This could have an amplifying instead of attenuating effect on the backscatter intensity, which explains the higher backscatter intensity during the growth period in July to October.

For cereals and sugar beet, backscatter intensity is highest in March. This could be due to frozen soils or ploughing activities. Indeed, March is the coldest month within the vegetation period, so that frozen soil could occur. For our observation years, a DWD climate station in Aachen recorded a mean air temperature of $6.6^{\circ} \mathrm{C}$. On the acquisition date of March 27, 1996 in the early morning and late evening air temperatures even below or close to 0 were recorded in Aachen. Since the ERS acquisition on that date was at 21:40, frozen soils are possible. However, since frozen soils are reported to result in a decrease in backscatter intensity, ${ }^{44-46}$ we accredit the higher backscatter in March to ploughing activities that are usual for that month. The ploughed soil could increase double bounce effects, due to high surface roughness and vertical surface structures. No clear seasonal evolution is expected for grassland, as biomass development depends on cutting dates and not on a specific agricultural cycle. This is supported by the boxplot that shows no clear seasonality but long whiskers. As no information about cutting dates is available and to apply a consistent method to all land use types, a monthly subdivision is used for grassland as well. 


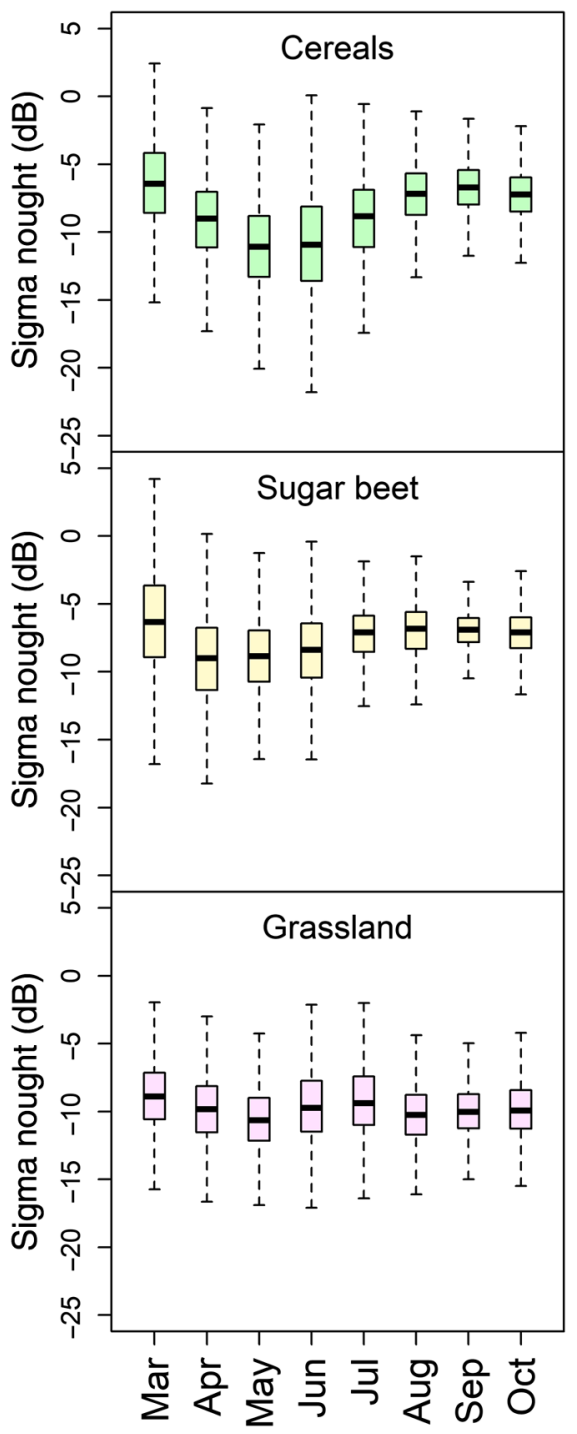

Fig. 3 Monthly boxplots of backscattering coefficient sigma nought $(\mathrm{dB})$ for different land use types during the vegetation periods of 1995 to 1997 and 1999 to 2003. The whiskers show the most extreme data point that is no more than 1.5 times the interquartile range.

The dependency of the dielectric constant (and thus sigma nought) on soil temperature has been examined in various studies. Considerable effects have been found from soil temperatures below zero, compared to soil temperatures above zero. ${ }^{47,48}$ For temperatures above the freezing point, contradictory results were reported, but the dependency of the relative dielectric constant to soil temperature was found to be influenced by the ratio of bulk to soil water. ${ }^{49}$ Since, with the exception of March 27, 1997, there are no days with temperatures below or close to zero occur in our dataset (based on hourly temperature measurements from the DWD climate station in Aachen), we assume a temperature influence on the dielectric constant as negligible.

By applying Eq. (1) to the 84 sigma nought maps, we produced maps showing the SMI values. Figure 4 exemplarily shows two of these maps. The map for April 16, 2002 shows overall wetter soil conditions in mean compared to the map of April 01, 2003, where the Eifel region seems to be wetter than the fertile loess plain. When comparing to the daily average precipitation, from the 10 DWD RR-stations within the Rur catchment, this is reasonable, as on April 16, 2002, there was 11.9-mm precipitation, with no clear difference between the fertile loess plain (RR1RR3) and the Eifel region (RR4-RR10). In mean, the day before occurred 11.7-mm precipitation and the 7-day antecedent precipitation was $24.9 \mathrm{~mm}$. On April 01, 2003, there was 15.7-mm precipitation. The Eifel stations (RR4-RR10) clearly show higher precipitation amounts than the 

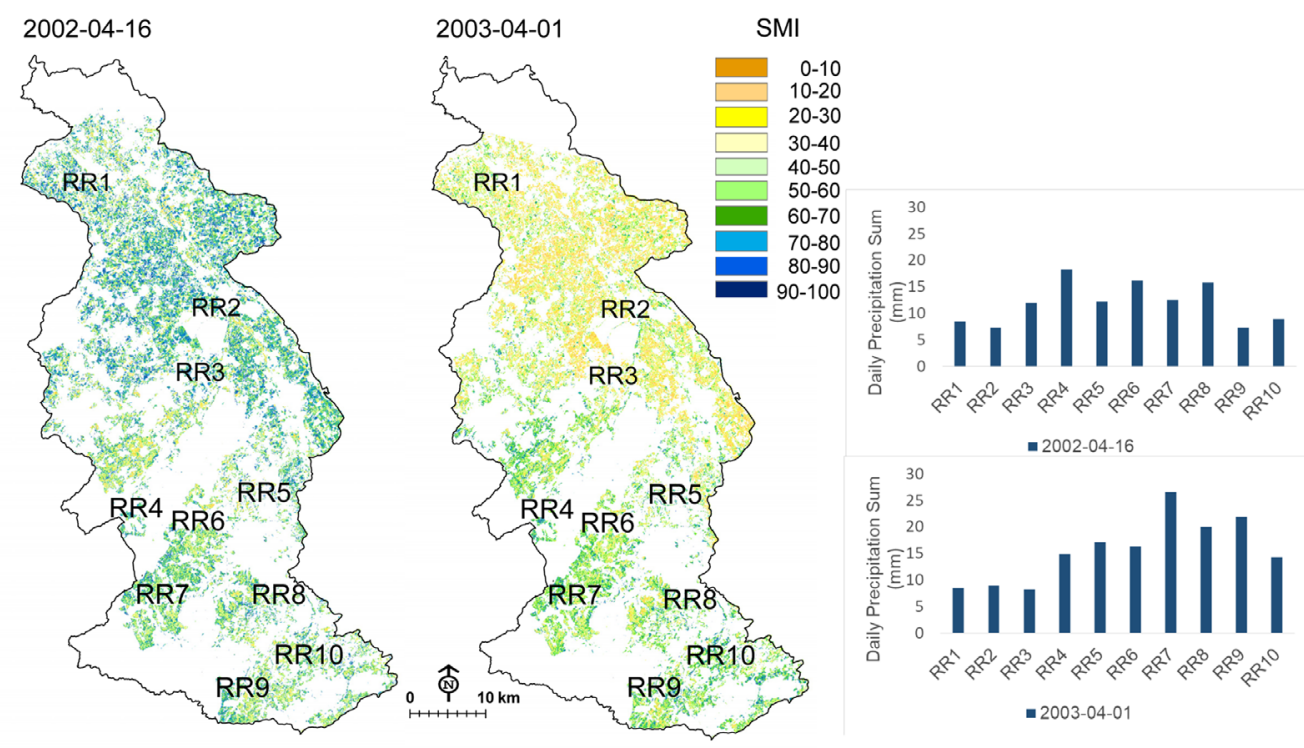

Fig. 4 SMI maps based on single pixels from April 16, 2002, and April 01, 2003, with corresponding precipitation sums at the 10 DWD stations introduced in Fig. 2. SMI classes range from 0 - very low, to 100- very high amount of soil moisture.

stations in the fertile loess plain (RR1-RR3) in Fig. 4. There was no precipitation the day before and 17.5-mm 7-day antecedent precipitation. On both days, the ERS acquisition took place in the morning at 10:27 so that, for both cases, the same day precipitation could have occurred after the acquisitions. To analyze the SMI more thoroughly, however, the differential SMI $(\Delta \mathrm{SMI})$ from the tandem acquisitions (two consecutive measurements in the same path with $24 \mathrm{~h}$ delay) is compared to precipitation data in the next section.

\subsection{ERS-1 and -2 Tandem Scenes for the Evaluation of Drying and Wetting Processes}

For the seven paired scenes of the tandem acquisition (Table 3), $\Delta$ SMI was calculated. On the map from March 26, 1996/March 27, 1996 (Fig. 5), we clearly see strong drying (red), whereas for April 30, 1996/May 01, 1996, we see wetting (blue) of the area. This is well in line with the measured daily precipitation at the 10 meteorological stations (Table 3). For the drying case, precipitation has been recorded at all stations on March 26, 1996. One day later, on March 27, 1996, only two stations show precipitation. This correlates with the "drying" indicated in the differential map. For the wetting case, no precipitation has been recorded at the stations on April 30, 1996, whereas on May 01, 1996, all stations recorded precipitation. Again, $\Delta$ SMI captures this development well. Looking at all seven tandem pairs, statistical $F$-tests and Levenetests between each tandem-pair showed inequality in variance for all cases. The subsequent Welch-tests showed significant differences in mean for each tandem pair. This indicates a clear change in the backscatter distribution from one to the next image in the tandem pairs. The mean $\Delta$ SMI and the number of pixels in each differential image, which display drying or wetting, were compared to precipitation at the different stations (Table 3). A positive tandem mean $\Delta$ SMI shows that the differential image illustrates a wetting tendency and a negative tandem mean $\Delta$ SMI shows a drying tendency. The effect of precipitation is well represented by the change in the tandem images, which can be accredited to a change in soil moisture. Precipitation situations without a clear trend, as on October 03, 1995/October 04, 1995 and on May 20, 1997/ May 21, 1997, result in an almost equal percentage of pixels showing wetting and drying tendencies and the mean of the differential tandem image is close to zero. In general, on dates where a drying or wetting can be expected from precipitation, this tendency can also be found in the $\Delta$ SMI. 
Table 3 Mean and standard deviation of precipitation $(\mathrm{mm})$ as measured at different stations for dates of tandem acquisitions with corresponding mean SMI difference $(\Delta \mathrm{SMI})$ and the percentage of wetting and drying pixels.

\begin{tabular}{|c|c|c|c|c|c|c|}
\hline \multirow[b]{2}{*}{ Date } & \multirow{2}{*}{$\begin{array}{c}\text { Mean } \\
\text { precipitation }(\mathrm{mm})\end{array}$} & \multirow[b]{2}{*}{$\begin{array}{c}\text { Standard } \\
\text { deviation }(\mathrm{mm})\end{array}$} & \multirow[b]{2}{*}{$\begin{array}{l}\text { Tandem } \\
\text { mean }\end{array}$} & \multicolumn{3}{|c|}{ Percentage of tendency } \\
\hline & & & & Drier & No change & Wetter \\
\hline October 03, 1995 & 3.3 & 2.1 & & & & \\
\hline October 04, 1995 & 7.0 & 2.8 & 5 & 40 & 2 & 58 \\
\hline March 26, 1996 & 2.2 & 0.8 & & & & \\
\hline March 27, 1996 & 0.2 & 0.5 & -20 & 84 & 1 & 15 \\
\hline April 11, 1996 & 3.5 & 1.4 & & & & \\
\hline April 12, 1996 & 0.1 & 0.1 & -21 & 83 & 1 & 16 \\
\hline April 30, 1996 & 0 & 0 & & & & \\
\hline May 01, 1996 & 7.5 & 3.8 & 35 & 4 & 0 & 95 \\
\hline June 20, 1996 & 5.8 & 1.4 & & & & \\
\hline June 21, 1996 & 0.2 & 0.4 & -12 & 74 & 2 & 24 \\
\hline October 22, 1996 & 0 & 0 & & & & \\
\hline October 23, 1996 & 0 & 0 & -1 & 50 & 2 & 48 \\
\hline May 20, 1997 & 6.3 & 2.1 & & & & \\
\hline May 21, 1997 & 3 & 3.0 & 0 & 50 & 3 & 47 \\
\hline
\end{tabular}

Differential Image

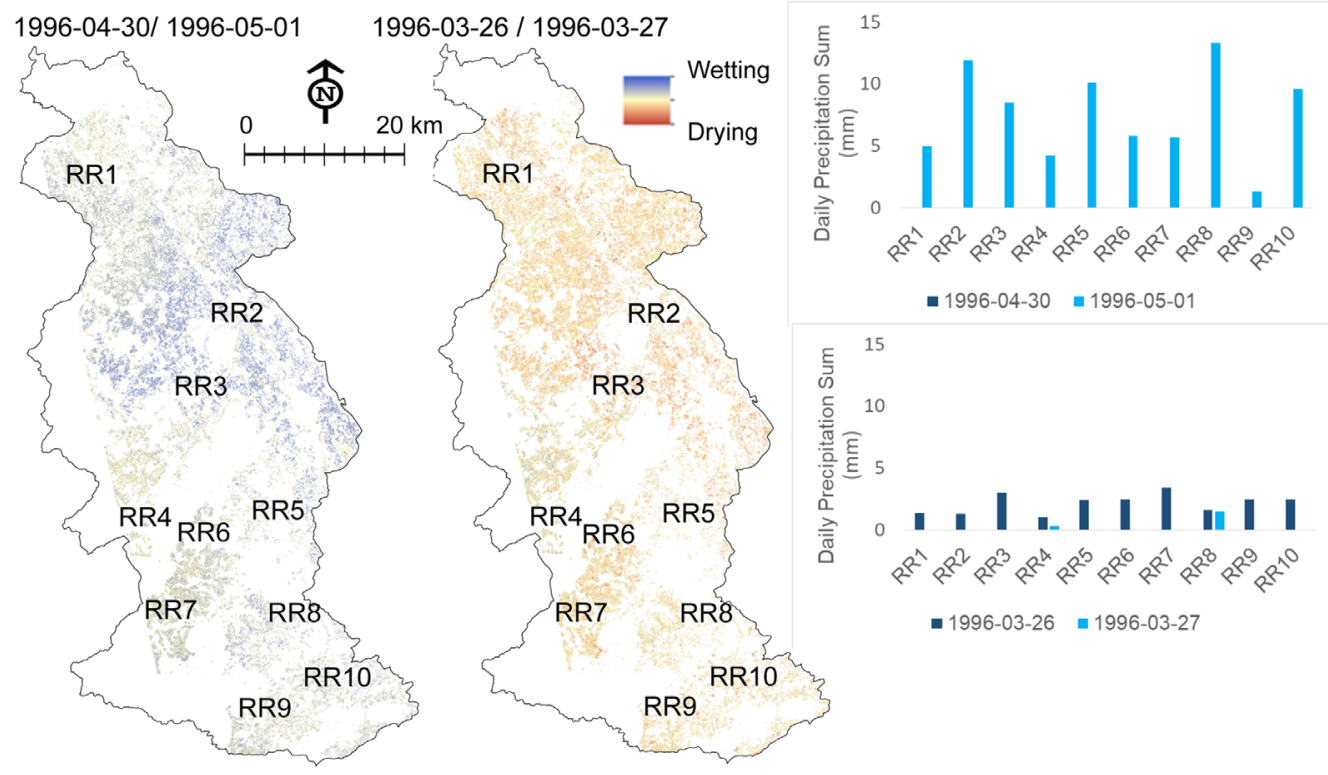

Fig. 5 Differential images $(\Delta S M I)$ for two ERS tandem pairs with corresponding precipitation for both days, of each pair, respectively, at the 10 DWD stations introduced in Fig. 2. Note that April 30, 1996, was a dry day everywhere in the test site and considerable rainfall fell on May 01, 1996. The opposite is true for the tandem scene March 26, 1996/March 27, 1996. 


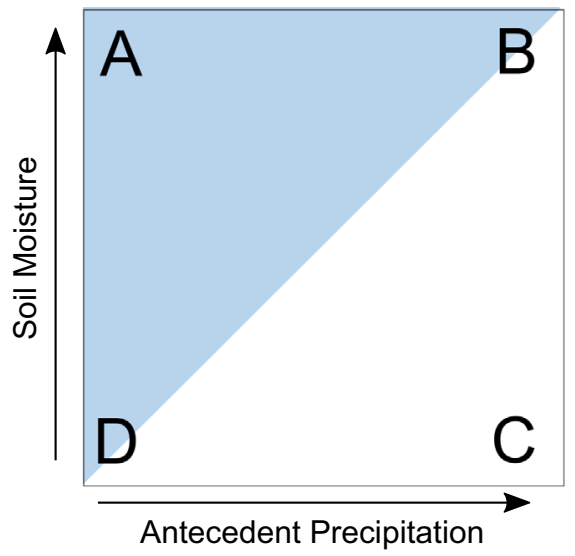

Fig. 6 Theoretical relationship between soil moisture and antecedent precipitation. The gray triangle shows the theoretically plausible area of values.

\subsection{Comparing the Soil Moisture Index to Antecedent Precipitation}

The previous section showed that the SMI represents wetting and drying tendencies due to precipitation well. In this section, we investigate whether the SMI shows a similar behavior with regards to antecedent precipitation as an in-situ soil moisture dataset does. So, SMI mean values at each station and in-situ soil moisture data were compared to corresponding antecedent precipitation sums.

The general relationship between antecedent precipitation and surface soil moisture is influenced by different factors as meteorological conditions (e.g., temperature and humidity) that regulate the evapotranspiration and also by interception and saturation state of the soil that are not considered in our analysis. Depending on these factors, the same antecedent precipitation can cause different soil moisture and thus different SMI values. Therefore, from a theoretical point of view, a strong correlation between SMI and antecedent precipitation is not to be expected. The relation of antecedent precipitation to soil moisture has the shape of a triangle (Fig. 6). Depending on the saturation state of the soil, low antecedent precipitation can result in low to high soil moisture. High antecedent precipitation can only result in high soil moisture unless there is sealing or crust formation of the soil.

To check if in-situ measured soil moisture values (Fig. 2) fulfil our theoretical scheme, we compared daily measurements from seven soil moisture sensors at meteo-stations at 5-cm depth with 7-day antecedent precipitation recorded at the same stations (Fig. 7). The measurements are from periods in 2014 to 2016 . Only measurements from the general vegetation period are used. The scatterplot fulfils the theoretical expectations and resembles Fig. 6.

A comparison of soil moisture index and 7-day antecedent precipitation at the 10 DWD stations and the soil moisture index in a $1-\mathrm{km}$ buffer around these stations (Fig. 8) also shows a behavior consistent with theoretical considerations and resembles Fig. 7. Low amounts of antecedent precipitation cause low to high SMI values but high amounts of antecedent precipitation do not cause low SMI values. The fact that both SMI and in-situ measured soil moisture react to antecedent precipitation in a similar way, which is additional evidence that the SMI in fact shows near-surface soil moisture state.

As mentioned before, no clear relationship between antecedent precipitation and near-surface soil moisture can be expected because of the many interacting factors that are involved (meteorological condition, saturation of the soil, etc.). To reduce this natural "scatter," we averaged the antecedent precipitation values according to SMI classes using 100 and 10 classes, respectively. Thus, the SMI class of 50 represents SMI value between 49.5 and 50.4 and in the case of 10 classes, SMI class of 5 represents SMI values between 44.5 and 54.4. For each SMI class, the antecedent precipitation was averaged. Figure 9 shows the resulting relationship of average antecedent precipitation height and SMI class. The resulting linear correlation is highly significant and shows an $R^{2}$ of 0.59 for 100 classes and 0.92 for 10 classes. Previous research 


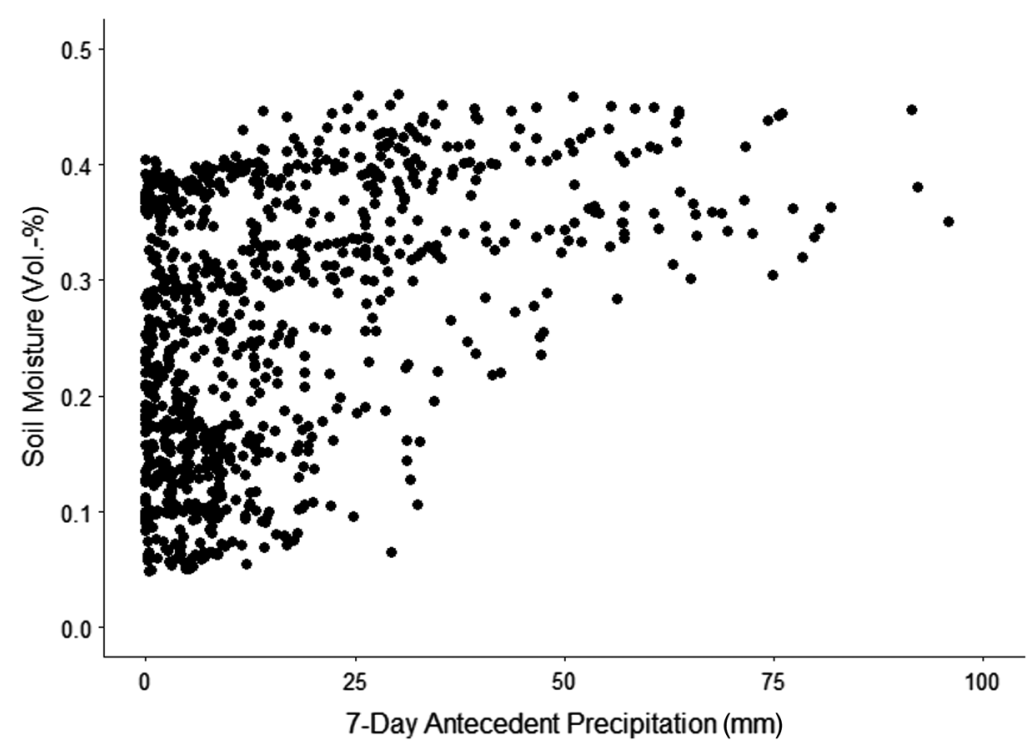

Fig. 7 Comparison of 7-day sum of antecedent precipitation with daily mean soil moisture from seven meteo stations within the Rur catchment. Continuous measurements were taken in $5-\mathrm{cm}$ depth. Data are from vegetation periods in 2014 to 2016.

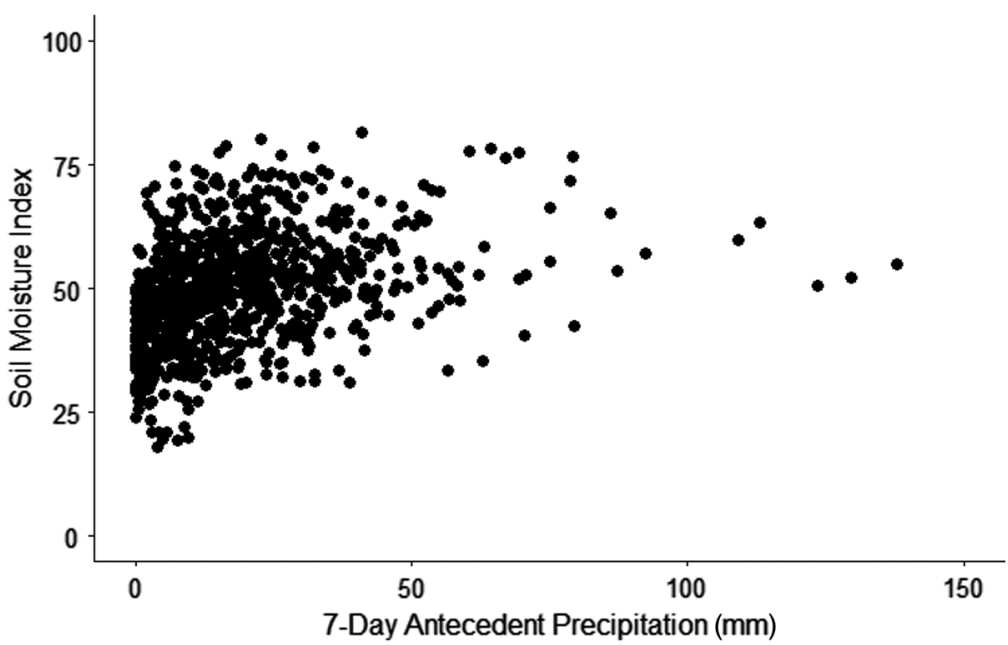

Fig. 8 Comparison of 7-day sum of antecedent precipitation with mean SMI for all DWD stations and ERS scenes.

found that five to ten classes of soil moisture are distinguishable with ERS data, as ERS-based soil moisture estimates have been found to provide an RMSE of about 5 to 10 vol.\%. ${ }^{19,50}$

Extreme SMI values between 0 and 10 and between 90 and 100 are very infrequent in the dataset. This did not change significantly when spanning the SMI between the 10th and 90th percentile instead of the 5th and 95th percentile (see Sec. 3.1). Very low and very high soil moisture is rarely found, especially when averaging over a larger area as we did within the $1 \mathrm{~km}$ buffer around the meteo-stations. This does not mean that our assumption of finding wet and dry pixels is incorrect, but it means that when averaging over a larger area, very dry and very wet situations are under-represented.

No improvement has been seen when calculating the correlation between soil moisture index and antecedent precipitation restricted to the crop areas and restricted to grassland areas, respectively. From that, we can conclude that there is no clear evidence that the soil moisture index performs different on one of the two land use types despite their different biomass development. 

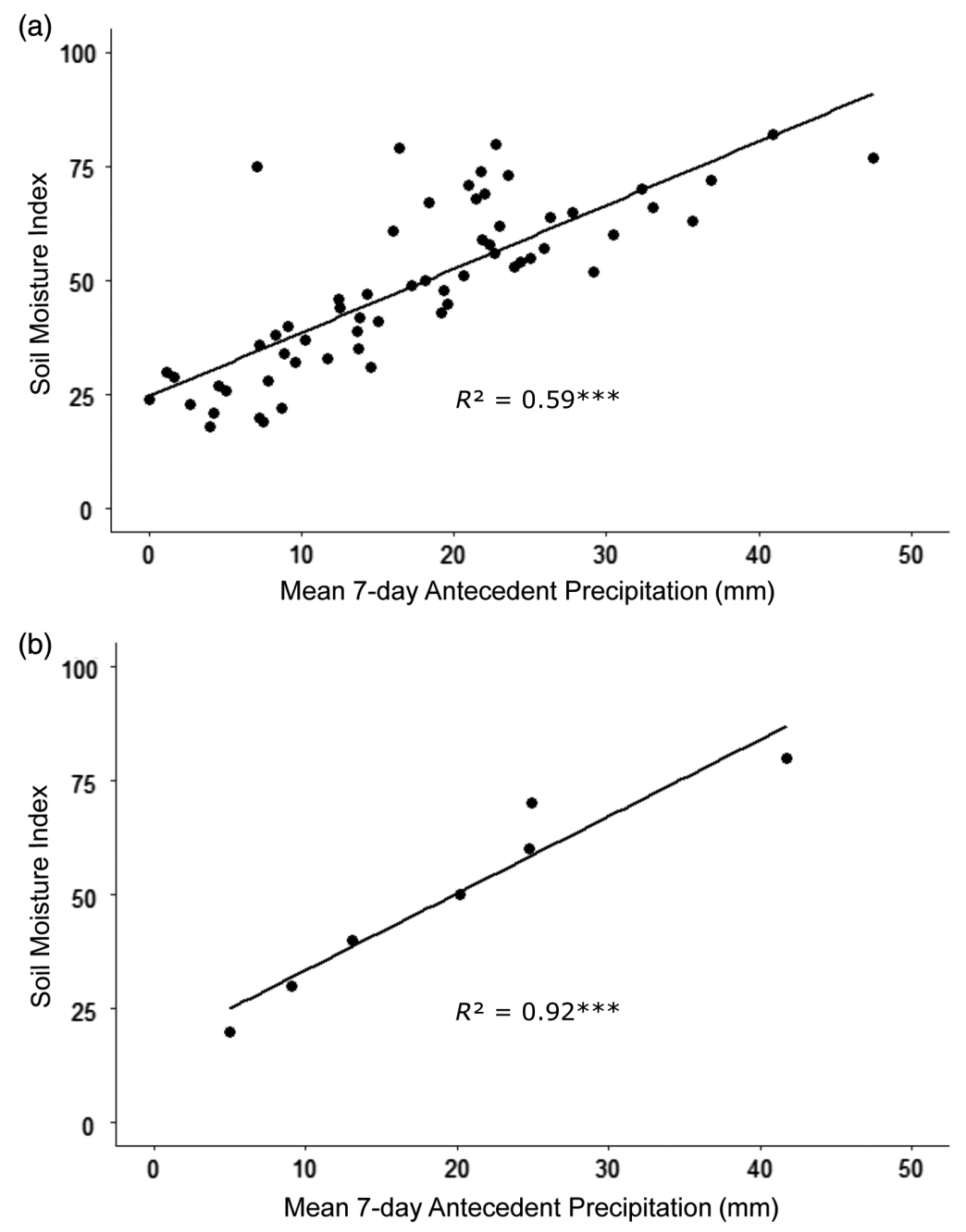

Fig. 9 Comparison of 7-day sum of antecedent precipitation averaged by SMI class with mean SMI for all stations and ERS-scenes. With (a) 100 classes ranging from 0 to 100 and (b) 10 classes ranging from 0 to 10 .

We performed the same analysis using an antecedent precipitation index based on Mattia et al. ${ }^{51}$ instead of antecedent precipitation and found comparable results.

The two evaluations presented in this section show that the SMI is able to display changes in the moisture state and behaves like in-situ soil moisture when compared to antecedent precipitation. Of course, low antecedent precipitation can still result in a high SMI, when, for example, evaporation is low and the soil is saturated. But, on average, low/high antecedent precipitation results in a low/high SMI, respectively, and a higher antecedent precipitation provokes the assignment of a higher soil moisture index value. Therefore, general patterns of SMI should be reliable although single pixel values are uncertain.

\subsection{Analysis of Spatial Heterogeneity}

Having a time series of SMI values at high spatial resolution provides the opportunity to examine the temporal or seasonal evolution of the spatial soil moisture structure and to find possible dependencies on soil moisture state. To assess which factors regulate the spatial distribution of surface soil moisture in the Rur catchment, we investigated the spatial heterogeneity of soil moisture and its structure.

It has been found that the theoretical relationship between standard deviation and mean soil moisture shows a unimodal shape, where standard deviation is highest at soil moisture values in 


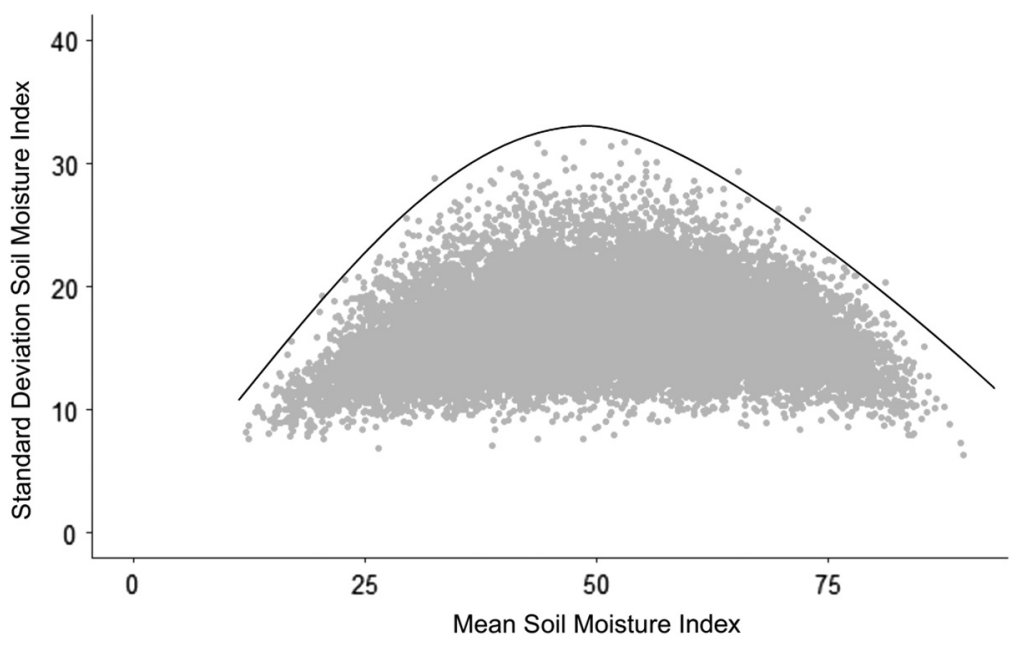

Fig. 10 Comparison of SMI standard deviation and SMI mean over the whole Rur-catchment and over all dates. The analysis has been performed in $140 \mathrm{~m} \times 140 \mathrm{~m}$ nonoverlapping boxes. The line shows the theoretical relationship between standard deviation and mean of soil moisture, as described in Bell et al. ${ }^{1}$ and Vereecken et al. ${ }^{20}$

the mid-range between field capacity and wilting point and is low in very wet or dry areas. ${ }^{1,20}$ The reduction in standard deviation of soil moisture under wet and dry conditions is due to the physical limits of saturation (100\%) and complete dryness (0\%). Thus, the spatial variability of soil moisture at extreme dry and wet states is controlled by spatial variability of soil properties, such as wilting point and porosity. When the soil reaches intermediate moisture conditions, spatial variability of soil moisture is regulated by spatial differences in the fluxes, especially of evapotranspiration. As evapotranspiration is highly heterogeneous in space, this provokes an increase in variability of soil moisture. Likewise, spatial differences in infiltration will have a regulating effect on the spatial variability of soil moisture. Spatial differences in infiltration depend to a high degree on spatial differences of soil texture. Since the soil texture in our research catchment is mainly homogenous (apart from the northernmost part of the catchment), we assume the influence of spatial differences in infiltration on spatial soil moisture variability secondary. When the soil dries further, the moisture distribution is influenced by spatial differences in the wilting point (which is less heterogeneous than evapotranspiration), thus decreasing the variability. ${ }^{1,20}$

To investigate whether similar behavior can be found in the SMI data, mean SMI value and standard deviation have been calculated for the whole Rur catchment. We chose $140 \times 140 \mathrm{~m}$ nonoverlapping boxes for the calculations since, in this small area, antecedent precipitation heights, soil types, and land use types are assumed to be homogenous. At intermediate mean SMI values, standard deviation shows a wide range of values up to a maximum standard deviation (Fig. 10). In dry areas (with low SMI mean) and wet areas (with high SMI mean), the range of standard deviations is low and no high standard deviation values are found. Thus, the outline of the distribution follows the findings mentioned above and shows the theoretically expected behavior of a soil moisture dataset.

This behavior is important, as it contradicts the argument that the soil moisture index could show effects of vegetation instead of soil moisture. If we assume for a moment that the soil moisture index reacts mainly to a vegetation signal and not a soil moisture signal, the increasing variability of the vegetation's state that emerges during the vegetation period would increase the variability in roughness and/or water content. This should lead to a increased backscatter variability (and hereby to an increased SMI variability). The relationship should probably saturate at a certain density but it would not decrease again. The decrease of variability at higher values of SMI in our data indicates that the soil moisture index method, despite its crude way of minimizing the vegetation influence, represents soil moisture and not vegetation water content or interception. 


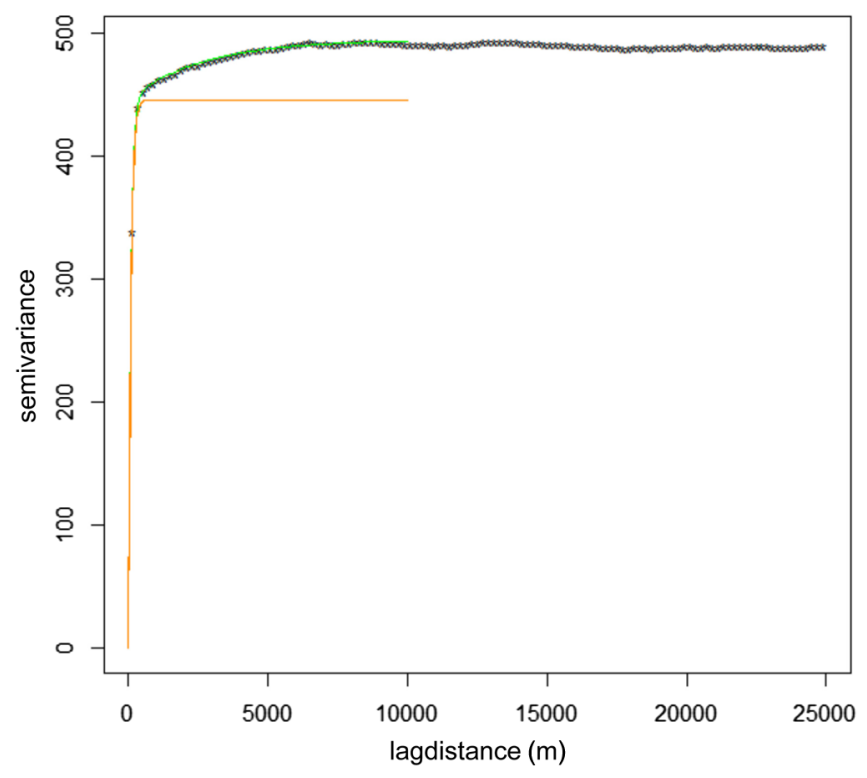

Fig. 11 Exemplary empirical semivariogram with simple exponential (orange) and nested exponential fit (green) showing June 06, 1997. The maximum lag for fitting has been set to $10 \mathrm{~km}$. The gamma value or semivariance describes the variance in the spatial relationship and is inverse to autocorrelation.

Semivariogram analysis reveals spatial patterns in the data and enables one to find causes of these patterns. In previous studies, a semivariogram analysis of surface soil moisture revealed temporal courses and dependencies on moisture state for range and sill values. ${ }^{22,41}$ For the current study, experimental and theoretical semivariograms were generated for the three different spatial units: (i) the whole catchment, (ii) the low mountain range of the Eifel, and (iii) the fertile loess plain. Most semivariograms could not be fitted well by a conventional model, so that a nested approach had to be applied (Fig. 11), where two semivariograms are added, resulting in a short and a long range. This implies that there are at least two spatial patterns that have an influence on the SMI in the Rur catchment. Theoretical semivariograms were fitted for lags up to $10 \mathrm{~km}$. In those cases, where simple and nested approaches failed to fit the experimental semivariogram, an exponential fit was used but restricted to a maximum lag of $3 \mathrm{~km}$ as only this resulted in acceptable fits. For the whole catchment, this was the case for 4 out of 84 dates, for the Eifel region, the simple exponential fit had been applied to 3 dates but on 4 dates, no model could be fitted at all. For the fertile loess plain again, all dates could be fitted, but for 16 out of 84 dates, the simple exponential fit has been chosen. This means that for these dates, we find several underlying influences at distances of more than $3 \mathrm{~km}$ that cannot be described. No commonality regarding season or soil moisture state could be found among these dates.

The short ranges for the whole catchment span between 264 and $606 \mathrm{~m}$, for the fertile loess plain between 276 and $672 \mathrm{~m}$, and those for the Eifel region between 246 and $783 \mathrm{~m}$. These scales correspond to typical field sizes found in the Rur catchment, so that we assume changes in agricultural management from one to the next field (e.g., crop type, phenological state, cutting dates on grassland) and thereby changes in evapotranspiration, are the dominating influence on the spatial structure of soil moisture on the smaller scale. Comparable ranges have been found by Reichenau et al. ${ }^{40}$ when analyzing the spatial structure of leaf area index (LAI) on arable land in the fertile loess plain.

To find factors that influence the spatial structure of soil moisture, we correlated the ranges determined in the semivariogram analysis with mean soil moisture and its standard deviation. We also searched for temporal patterns, e.g., distinctive features in specific years or months or specific temporal courses. Short ranges are compared to standard deviation of soil moisture (which correlates with sill) in Fig. 12. For the whole Rur catchment and for the fertile loess plain, a slight negative trend, though highly variable, can be observed. This trend can be described by a negative linear correlation with an $R^{2}$ of 0.14 for the whole Rur catchment and an $R^{2}$ of 0.20 for the 


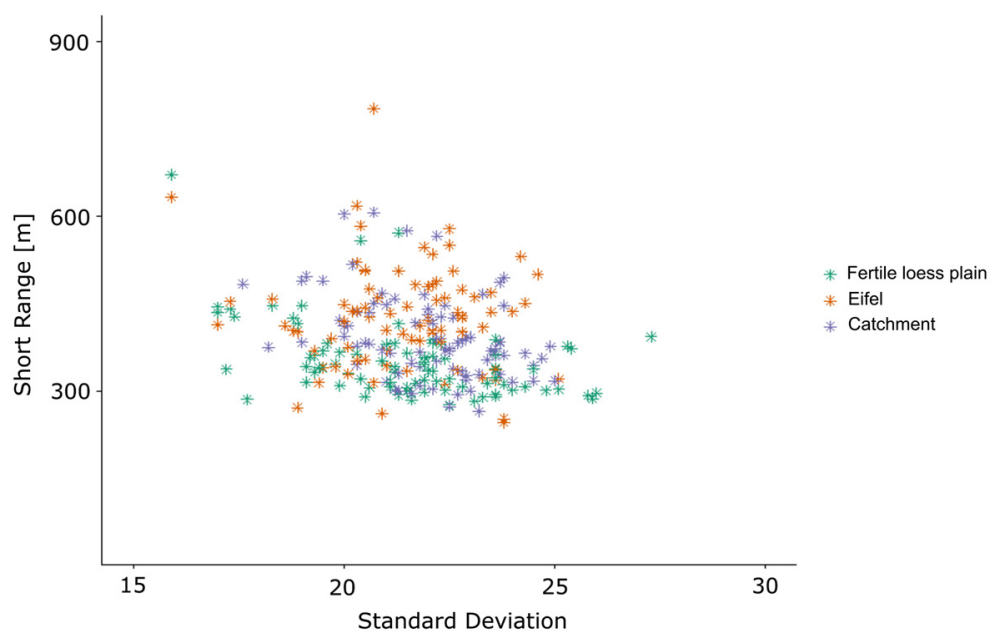

Fig. 12 Relationship of short range to standard deviation of SMI for the fertile loess plain, Eifel, and the whole catchment.

fertile loess plain. Both relationships are highly significant with a $p$-value $<0.001$. The negative trend is reasonable as we expect to find a faster decrease in autocorrelation with distance, the more variable soil moisture is. For the Eifel region alone, no significant trend is found in the data. The short range values for the Eifel region are, in general, slightly higher but also more variable than in the other two areas. This is explained well by the fact that the Eifel is mainly characterized by grassland areas that usually have no clear field borders but span larger areas and are influenced by heterogeneous terrain. Statistical $f$ - and $t$-/Welch-tests have shown that the variance is equal for the range values calculated from the fertile loess plain and the whole catchment and also for the values from the Eifel region and the whole catchments. The mean values for both samples are unequal. The range values from the fertile loess plain, though, show inequality in variance and mean when compared to the range values from the Eifel region, indicating that the short range values calculated for the fertile loess plain and the Eifel region are substantially different. A comparison of short ranges with mean SMI neither shows a trend neither for the whole Rur catchment nor for the fertile loess plain or the Eifel region separately (Fig. 13). Thus, in our data, the spatial structure of SMI is not correlated with the mean soil moisture state. This leads to the assumption that the SMI is too variable to be represented by a single value for the whole catchment (or fertile loess plain or Eifel region). Therefore, a comparison between such mean value (that should represent the general moisture state of

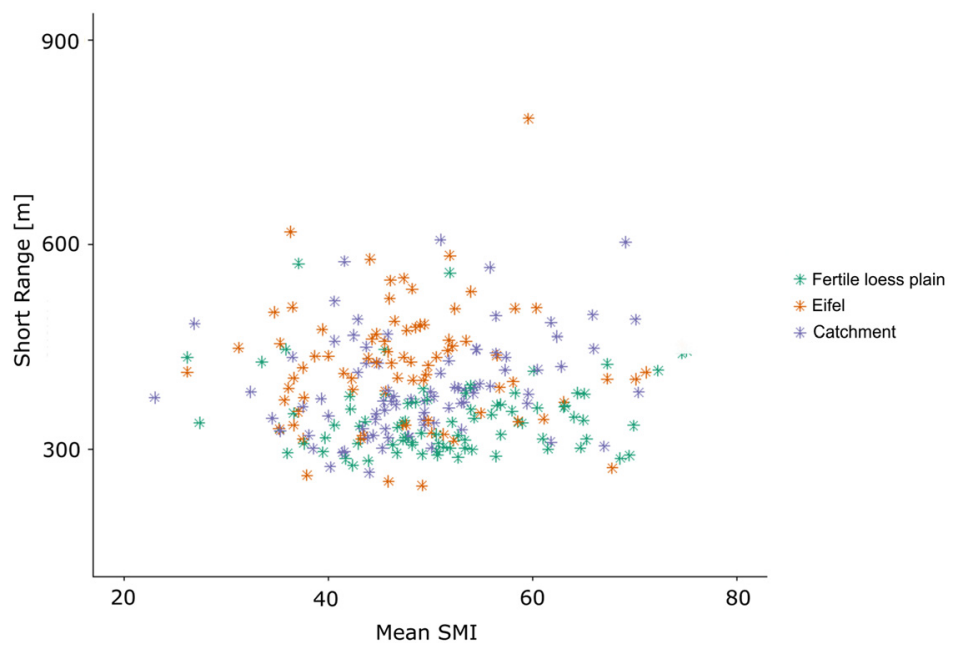

Fig. 13 Relationship of short range to mean SMI for the fertile loess plain, Eifel, and the whole catchment. 


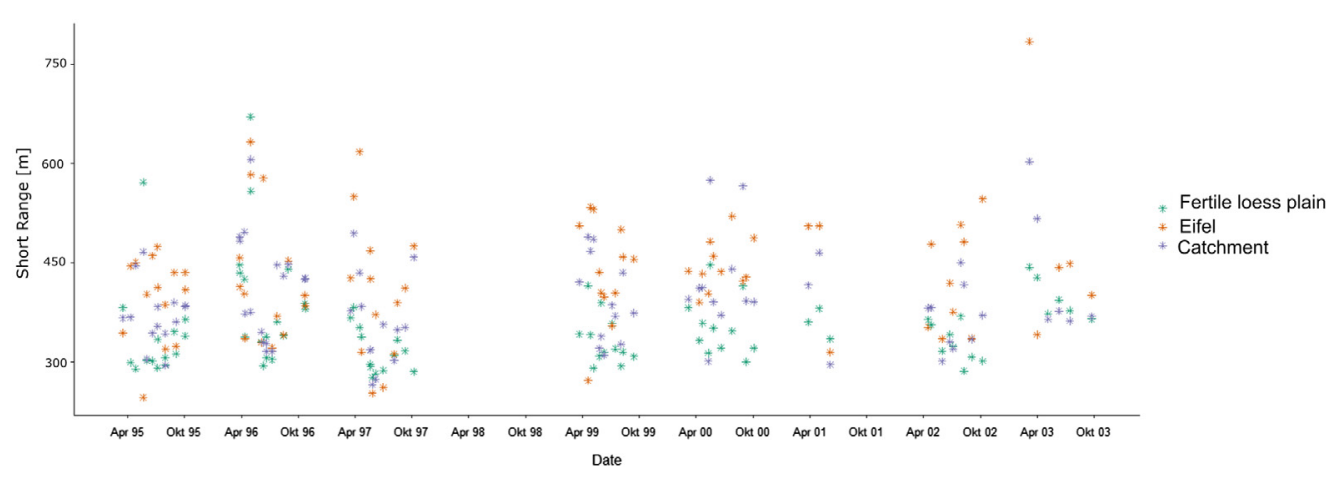

Fig. 14 Temporal evolution of short ranges in the whole Rur catchment, the Eifel region, and the fertile loess plain.

the observed area) and the short ranges might not be meaningful. The temporal evolution of the short range values is analyzed in Fig. 14. Here, no trend can be recognized either. This could be accredited to the low temporal frequency of the data, which makes small-scale changes invisible. What can be seen is that, in 2003, the short ranges do not reach values as low as in the other years. This might be an effect of the 2003 European heat wave that also struck Germany. Due to the drought, the vegetation influence on the spatial structure might have decreased, resulting in missing low short range values.

Korres et al. ${ }^{41}$ examined remotely sensed soil moisture products of the fertile loess plain of the Rur catchment with a spatial resolution of 15 and $150 \mathrm{~m}$. They found mean ranges at $432 \mathrm{~m}$ at $15-\mathrm{m}$ resolution and $711 \mathrm{~m}$ at $150-\mathrm{m}$ resolution using an un-nested approach. These range values were associated with land use structure. In contrast to other datasets used in the study, no dependence on soil parameters could be identified with the semivariogram analysis for the remotely sensed soil moisture. The results of Korres et al. ${ }^{41}$ are in line with the results of the current study.

Analyzing the long ranges for the cases, where a nested fit has been applied, is more complicated, as these ranges vary a lot, up to maximum long ranges found at about $1500 \mathrm{~km}$, when the theoretical semivariogram does not converge optimally. In median, anyways, the long range is found at a length of about $12 \mathrm{~km}$. The 10th and the 90th percentiles of the long range distribution are 5.4 and $117.6 \mathrm{~km}$, respectively, thus spanning a realistic range. Influences could be attributed to soil type, topography, or local precipitation but cannot be clearly distinguished. The long ranges found in this study are higher than those found by Reichenau et al. ${ }^{40}$ but at a comparable scale. They also attributed these ranges to effects of soil or weather.

In summary, the only clearly recognizable effect on the spatial structure of SMI in our study is the field size. This has been found as a major influence in the Rur catchment before Reichenau et al. ${ }^{40}$ and Korres et al. ${ }^{41}$ As we had the opportunity to analyze a long time series of soil moisture data, we had expected to find temporal or seasonal trends in the soil moisture structure due to weather or climate influence on soil moisture distribution or a dependency on the soil moisture state like for soil moisture variability, since such effects have been found in soil moisture datasets before Western et al. ${ }^{22}$ and Korres et al. ${ }^{41}$ Contrary to expectation, no such trend or dependency has been found in our data. Since Korres et al. ${ }^{41}$ found a dependency of range on soil moisture variability for the same research catchment, we had expected to find something similar. Also, we expected to find a clear signal of the two different landscape units, the fertile loess plain and the Eifel. Our results indicate that the soil moisture index, at least with this spatiotemporal resolution, is not suitable to identify more complex factors that influence the structure of soil moisture in our catchment. But also the fact that we do not have spatially continuous data, since land use types like, e.g., forests, were masked out, might not allow us to find more structure in the data.

\section{Conclusions and Outlook}

The soil moisture index approach is an easily applicable method for assessing wetting and drying tendencies and patterns of near-surface soil moisture in the absence of ground truth data for 
calibration. The only necessary input data is a land use map and a long time series of SAR images. Both are available through remote sensing data from, e.g., ERS and Landsat. Ground truth data that is needed to train the land use classifications could be substituted by information from aerial images or could be collected by referring to agricultural statistics. This makes a soil moisture index method interesting for historic analysis and applications in data scarce regions. In addition, assessing the near-surface soil moisture state by SMI maps can complement the frequently used antecedent precipitation in hydrologic models.

Both types of evaluation, analyzing wetting and drying tendencies and comparing the SMI to antecedent precipitation, have shown that the properties of the soil moisture index SMI data are in line with those of in-situ soil moisture:

1. The comparison of tandem scenes showed that moisture changes due to precipitation are well represented in most soil moisture index maps. This makes the soil moisture index a valuable tool to assess moisture tendencies, e.g., for drought monitoring.

2. The relationship of the SMI and 7-day antecedent precipitation is comparable to the relationship of in-situ measured soil moisture and corresponding 7-day antecedent precipitation. When averaged, the SMI shows a strong linear correlation with antecedent precipitation. Therefore, it can complement antecedent precipitation as input to hydrological studies and can be used to derive qualitative information, such as soil moisture patterns.

In general, the SMI can be used to monitor temporal developments of near-surface soil moisture (e.g., for drought monitoring), give qualitative information about surface soil moisture distributions, and could improve hydrological models. The quality of the SMI itself depends, of course, highly on the accuracy of the underlying land use classification and the extent of the time series of SAR-data.

The analysis of spatial variability of the SMI showed behavior as described in theory for soil moisture. This indicates that the SMI can be used for the analysis of spatial soil moisture variability without the need of in-situ soil moisture measurements.

Contrary to expectations, the only influence on the soil moisture structure in the Rur catchment is the difference in management and hereby in evapotranspiration, expressed by the field borders. Therefore, index-based soil moisture information may not be sufficient to identify more complex factors that influence the soil moisture structure. For such analysis, quantitative soil moisture information from ground measurements or (semi-) empirical remote sensing-based soil moisture retrieval methods might be indispensable. Alternatively, an index-based method applied to SAR data with higher spatial and radiometric resolution could provide suitable data for structural analysis.

Since no ground truth data were available to validate the SMI approach and the approach could only be evaluated, future research should test the approach with Sentinel-1A/B data. The availability of ground based measurements would also provide the data needed to explore the conversion of SMI values into volumetric soil moisture. The higher spatial, radiometric, and temporal resolution of Sentinel data could provide a more complete time series of SMI maps that could significantly improve the potential to analyze spatial soil moisture structure. Also, a better land use map, based on a higher number of optical satellite scenes, has the potential to improve the quality of the SMI results. Furthermore, integrating a SAR-based SMI approach with coarse scale passive microwave remote sensing products might provide a promising downscaling approach. Coarse scale soil moisture products are available from various satellite platforms, such as SMOS and SMAP satellites.

\section{Acknowledgments}

We gratefully acknowledge financial support by the SFB/TR32 "Patterns in Soil-VegetationAtmosphere Systems: Monitoring, Modelling, and Data Assimilation" funded by the German Science Foundation (DFG). We would also like to thank the European Space Agency (ESA) for the provision of the ERS-SAR data through their PI-program (AOALO.3570). We also thank the two anonymous reviewers for their helpful comments. 


\section{References}

1. K. R. Bell et al., "Analysis of surface moisture variations within large-field sites," Water Resour. Res. 16(4), 796-810 (1980).

2. T. Blume, E. Zehe, and A. Bronstert, "Use of soil moisture dynamics and patterns at different spatio-temporal scales for the investigation of subsurface flow processes," Hydrol. Earth Syst. Sci. 13(7), 1215-1233 (2009).

3. J. Famiglietti et al., "Ground-based investigations of soil-moisture variability within remote sensing footprints during the Southern Great Plains 1997 (SGP97) hydrology experiment," Water Resour. Res. 35(6), 1839-1851 (1999).

4. B. P. Mohanty, T. H. Skaggs, and J. S. Famiglietti, "Analysis and mapping of field-scale soil moisture variability using high-resolution, ground-based data during the Southern Great Plains 1997 (SGP97) hydrology experiment," Water Resour. Res. 36(4), 1023-1031 (2000).

5. T. J. Schmugge and T. J. Jackson, "Soil moisture variability," in Scaling Up in Hydrology Using Remote Sensing, J. B. Stewart et al., Eds., pp. 183-192, John Wiley \& Sons, Chichester, England (1996).

6. E. T. Engman, "Applications of microwave remote-sensing of soil-moisture for waterresources and agriculture," Remote Sens. Environ. 35(2-3), 213-226 (1991).

7. T. J. Jackson, J. Schmugge, and E. T. Engman, "Remote sensing applications to hydrology: soil moisture," Hydrol. Sci. J. 41(4), 517-530 (1996).

8. C. H. Roth, M. A. Malicki, and R. Plagge, "Empirical-evaluation of the relationship between soil dielectric-constant and volumetric water-content as the basis for calibrating soilmoisture measurements by TDR," Eur. J. Soil Sci. 43(1), 1-13 (1992).

9. T. J. Schmugge, T. J. Jackson, and H. L. Mckim, "Survey of methods for soil-moisture determination," Water Resour. Res. 16(6), 961-979 (1980).

10. G. C. Topp, J. L. Davis, and A. P. Annan, "Electromagnetic determination of soil-water content-measurements in coaxial transmission-lines," Water Resour. Res. 16(3), 574582 (1980).

11. D. P. Thoma et al., "Comparison of four models to determine surface soil moisture from C-band radar imagery in a sparsely vegetated semiarid landscape," Water Resour. Res. 42(1), 1-12 (2006).

12. N. E. C. Verhoest et al., "On the soil roughness parameterization problem in soil moisture retrieval of bare surfaces from synthetic aperture radar," Sensors 8(7), 4213-4248 (2008).

13. A. K. Fung, Z. Q. Li, and K. S. Chen, "Backscattering from a randomly rough dielectric surface," IEEE Trans. Geosci. Remote Sens. 30(2), 356-369 (1992).

14. T. Jagdhuber, I. Hajnsek, and K. P. Papathanassiou, "Polarimetric soil moisture retrieval using an iterative generalized hybrid decomposition technique," in IEEE Geoscience and Remote Sensing Symp. (2014).

15. I. Hajnsek et al., "Potential of estimating soil moisture under vegetation cover by means of PolSAR," IEEE Trans. Geosci. Remote Sens. 47(2), 442-454 (2009).

16. N. Baghdadi et al., "Semi-empirical calibration of the IEM backscattering model using radar images and moisture and roughness field measurements," Int. J. Remote Sens. 25(18), 3593-3623 (2004).

17. C. N. Koyama and K. Schneider, "A novel approach to estimate soil moisture under vegetation using partial polarimetric ALOS PALSAR data," in ISPRS Commission VIII Symp., Kyoto, Japan (2010).

18. Y. Oh, "Quantitative retrieval of soil moisture content and surface roughness from multipolarized radar observations of bare soil surfaces," IEEE Trans. Geosci. Remote Sens. 42(3), 596-601 (2004).

19. M. Rombach and W. Mauser, "Multi-annual analysis of ERS surface soil moisture measurements of different land uses," in 3rd ERS Symp., Florence, Italy (1997).

20. H. Vereecken et al., "Explaining soil moisture variability as a function of mean soil moisture: a stochastic unsaturated flow perspective," Geophys. Res. Lett. 34(22), L22402 (2007).

21. W. Korres, T. G. Reichenau, and K. Schneider, "Patterns and scaling properties of surface soil moisture in an agricultural landscape: an ecohydrological modeling study," J. Hydrol. 498, 89-102 (2013). 
22. A. W. Western, G. Blöschl, and R. B. Grayson, "Geostatistical characterisation of soil moisture patterns in the Tarrawarra catchment," J. Hydrol. 205(1-2), 20-37 (1998).

23. S. K. Tomer et al., "Retrieval and multi-scale validation of soil moisture from multi-temporal SAR data in a semi-arid tropical region," Remote Sens. 7(6), 8128-8153 (2015).

24. W. Wagner, G. Lemoine, and H. Rott, "A method for estimating soil moisture from ERS scatterometer and soil data," Remote Sens. Environ. 70(2), 191-207 (1999).

25. E. E. Sano et al., "Relation between ERS-1 synthetic aperture radar data and measurements of surface roughness and moisture content of rocky soils in a semiarid rangeland," Water Resour. Res. 34(6), 1491-1498 (1998).

26. E. Brunotte, R. Immendorf, and R. Schlimm, "Die Naturlandschaft und ihre Umgestaltung durch den Menschen: Erläuterungen zur Hochschulexkursionskarte Köln und Umgebung," Selbstverlag Geographisches Institut der Universität zu Köln, Köln, Germany (1994).

27. H. Bogena et al., MOSYRUR-Water Balance Analysis in the Rur Basin, Schriften des Forschungszentrums Jülich, Reihe Umwelt, Jülich, Germany (2005).

28. J.-S. Lee, "Speckle suppression and analysis for synthetic aperture radar images," Opt. Eng. 25(5), 255636 (1986).

29. scilands GmbH, "Digital Elevation Model 10 Without Anthropogenic Landforms," Göttingen, Germany (2010).

30. R Core Team, "R: a language and environment for statistical computing," $R$ Foundation for Statistical Computing, Vienna, Austria (2015).

31. C. Montzka, "Einsatz von multispektralen Satellitenbilddaten in der Wasserhaushalts- und Stoffstrommodellierung—dargestellt am Beispiel des Rureinzugsgebietes," Vol. 1, Schriften des Forschungszentrums Jülich Reihe Energie und Umwelt, Jülich, Germany (2008).

32. DWD Climate Data Center (CDC), "Historical daily precipitation observations for Germany," Version v005 (2017).

33. F. T. Ulaby, P. C. Dubois, and J. van Zyl, "Radar mapping of surface soil moisture," J. Hydrol. 184(1-2), 57-84 (1996).

34. F. Mattia et al., "Multitemporal C-band radar measurements on wheat fields," IEEE Trans. Geosci. Remote Sens. 41(7), 1551-1560 (2003).

35. F. T. Ulaby, P. P. Batlivala, and M. C. Dobson, "Microwave backscatter dependence on surface roughness, soil moisture, and soil texture: part I-bare soil," IEEE Trans. Geosci. Electron. 16(4), 286-295 (1978).

36. M. Zribi et al., "New methodology for soil surface moisture estimation and its application to ENVISAT-ASAR multi-incidence data inversion," Remote Sens. Environ. 96(3-4), 485-496 (2005).

37. F. Pan, C. D. Peters-Lidard, and M. J. Sale, "An analytical method for predicting surface soil moisture from rainfall observations," Water Resour. Res. 39(11), 1314 (2003).

38. S. Ali, N. C. Ghosh, and R. Singh, "Rainfall-runoff simulation using a normalized antecedent precipitation index," Hydrol. Sci. J. 55(2), 266-274 (2010).

39. S. Garrigues et al., "Quantifying spatial heterogeneity at the landscape scale using variogram models," Remote Sens. Environ. 103(1), 81-96 (2006).

40. T. G. Reichenau et al., "Spatial heterogeneity of leaf area index (LAI) and its temporal course on arable land: combining field measurements, remote sensing and simulation in a comprehensive data analysis approach (CDAA)," PLoS One 11(7), e0158451 (2016).

41. W. Korres et al., "Spatio-temporal soil moisture patterns-a meta-analysis using plot to catchment scale data," J. Hydrol. 520, 326-341 (2015).

42. E. J. Pebesma, "Multivariable geostatistics in S: the gstat package," Comput. Geosci. 30(7), 683-691 (2004).

43. K. W. Oleson et al., "Technical description of version 4.5 of the community land model (CLM)," in NCAR Technical Note, NCAR Earth System Laboratory Boulder, Colorado (2013).

44. E. Rignot et al., "Monitoring of environmental conditions in Taiga forests using ERS-1 SAR," Remote Sens. Environ. 49(2), 145-154 (1994).

45. N. V. Smith, S. S. Saatchi, and J. T. Randerson, "Trends in high northern latitude soil freeze and thaw cycles from 1988 to 2002," J. Geophys. Res. 109(D12), D12101 (2004). 
46. U. Wegmüller, "The effect of freezing and thawing on the microwave signatures of bare soil," Remote Sens. Environ. 33(2), 123-135 (1990).

47. P. Hoekstra and A. Delaney, "Dielectric properties of soils at UHF and microwave frequencies," J. Geophys. Res. 79(11), 1699-1708 (1974).

48. M. Hallikainen et al., "Microwave dielectric behavior of wet soil-part 1: empirical models and experimental observations," IEEE Trans. Geosci. Remote Sens. 23, 25-34 (1985).

49. J. M. Wraith and D. Or, "Temperature effects on soil bulk dielectric permittivity measured by time domain reflectometry: experimental evidence and hypothesis development," Water Resour. Res. 35(2), 361-369 (1999).

50. A. Quesney et al., "Estimation of watershed soil moisture index from ERS/SAR data," Remote Sens. Environ. 72(3), 290-303 (2000).

51. F. Mattia et al., "Soil moisture retrieval through a merging of multi-temporal L-band SAR data and hydrologic modelling," Hydrol. Earth Syst. Sci. 13(3), 343-356 (2009).

Sabrina Esch received her diploma in geography in 2013 and her doctorate in physical geography in 2018, both from the University of Cologne, Germany. She is a research associate at the chair for hydrology and climatology at the University of Cologne. Among her current research interests are SAR remote sensing of soil moisture and vegetation parameters, SAR-data processing, and SAR polarimetry. Her focus is on agricultural areas.

Wolfgang Korres is a research associate at the chair for hydrology and climatology at the University of Cologne, Germany. He received his diploma in geography in 2006 and his doctorate in physical geography in 2013 from the University of Cologne. His research mainly focuses on remote sensing, field measurements, and modelling of water fluxes and plant growth in soil-vegetation-atmosphere systems and the analysis of spatiotemporal patterns within these systems.

Tim G. Reichenau is a research associate at the hydrology and climatology chair at the University of Cologne. He received his diploma in biology in 2000 and his doctorate in biology (geobotany) in 2009 from Giessen University. His research focuses on exchange processes of matter and energy between soil, vegetation, and atmosphere. His main interests are numerical simulations of biogeochemical cycles including anthropogenic impacts and the analysis of spatiotemporal patterns of system states and processes.

Karl Schneider is professor for hydrology and climatology. He received his diploma in hydrology and his PhD in geography from the University Freiburg in 1987 and 1991, respectively. After completing his habilitation in 1999 at University Munich, he became associate professor at the University of Toledo in 2001, and in 2002, he became a professor at the University of Cologne. His research focuses on remote sensing and integrative modelling of water, carbon, and nitrogen fluxes. 